\title{
Electrochemical impedance spectroscopy as a mean of measuring film thickness of calcium sulfate precipitate on an XC70 carbon steel
}

\author{
Touhami Lanez*, Nacer Chaabia, Amina Belaid \\ VTRS Laboratory, Faculty of Sciences and Technology, University of El Oued, \\ PO Box 789, 39000, El Oued, Algeria \\ *E-mail address: touhami-lanez@univ-eloued.dz
}

\begin{abstract}
In this paper we present the use of electrochemical impedance spectroscopy measurement as a tool to measure the thickness of calcium sulphate film formed on an XC70 carbon steel. The solution used is a mixture of sodium sulphate and calcium chloride solution at different concentrations. The film thickness of calcium sulphate is estimated, after an immersion time of 4 days. The results indicate reciprocal relationship between measured capacitance and thickness of calcium sulphate film.
\end{abstract}

Keywords: EIS; calcium sulphate; thickness

\section{INTRODUCTION}

Usually at the first stage of production only a small fraction of crude oil contained in the reservoir (about $30 \%$ ) can be recovered, in this case oil is spontaneously extracted under the only effect of the pressure in the reservoir. As the extraction of crude oil continued, the internal pressure of the reservoir decreases towards atmospheric pressure. This decrease in reservoir pressure affect the yield of the recovery of crude oil from the reservoir [1].

For many years, research has been conducted to improve the ultimate recovery of reserves of crude oil, one of the most commonly used method is called "Secondary" or "Enhanced recovery" and is consist of injection of albian water into the formation, but this injection can cause deposition of calcium sulphate which can provoke blockage of the reservoir rock, due to the incompatibility between the injected albian water, extracted from albian aquifer with high concentration of sulphate ions and formation waters, with high concentrations of calcium ions [2-3].

Deposition of calcium sulphates can cause serious damage to equipment and installations such as water injection system, pumps, tubing, casing flow-lines, heater theaters, tanks and other production equipment [4-8].

This present work is a contribution to estimate the quantity of calcium sulphate precipitation on an XC70 carbon steel using electrochemical impedance spectroscopy (EIS) measurements. 


\section{EXPERIMENTAL}

EIS measurements were performed with PGP301 Potentiostat/Galvanostat in a frequency range between $100 \mathrm{kHz}$ and $10 \mathrm{mHz}$, using a conventional three-electrode cell with a platinum wire as the auxiliary electrode and an $\mathrm{Hg} / \mathrm{Hg}_{2} \mathrm{Cl}_{2}$ (saturated with $\mathrm{KCl}$ ) as reference. Working electrode was an XC70 carbon steel with a surface of $7.07 \mathrm{~mm}^{2}$. Before use, it was carefully polished to a mirror finish with $1.0,0.3$, and $0.05 \mu \mathrm{m}$ alumina slurries, successively. The working electrode was then immerged in a solution of a mixture of sodium sulphate/calcium chloride at concentration of 79.5/5, 37.95/2.25, 18.85/1.25 g/l. The results are represented graphically using complex plane Nyquist plots.

\section{RESULTS AND DISCUSSION}

Figure 1, shows a variation in impedance values as function of electrolyte concentration. It can be seen that calcium sulphate precipitate film, formed on XC70 carbon steel, behaved as a very low capacitor in low solutions of low concentration of calcium and sulphate ions, this can be attributed to non-homogeneity of the surface layer of the precipitate itself. The curves show that there are important variations in impedance values at high solution concentration.

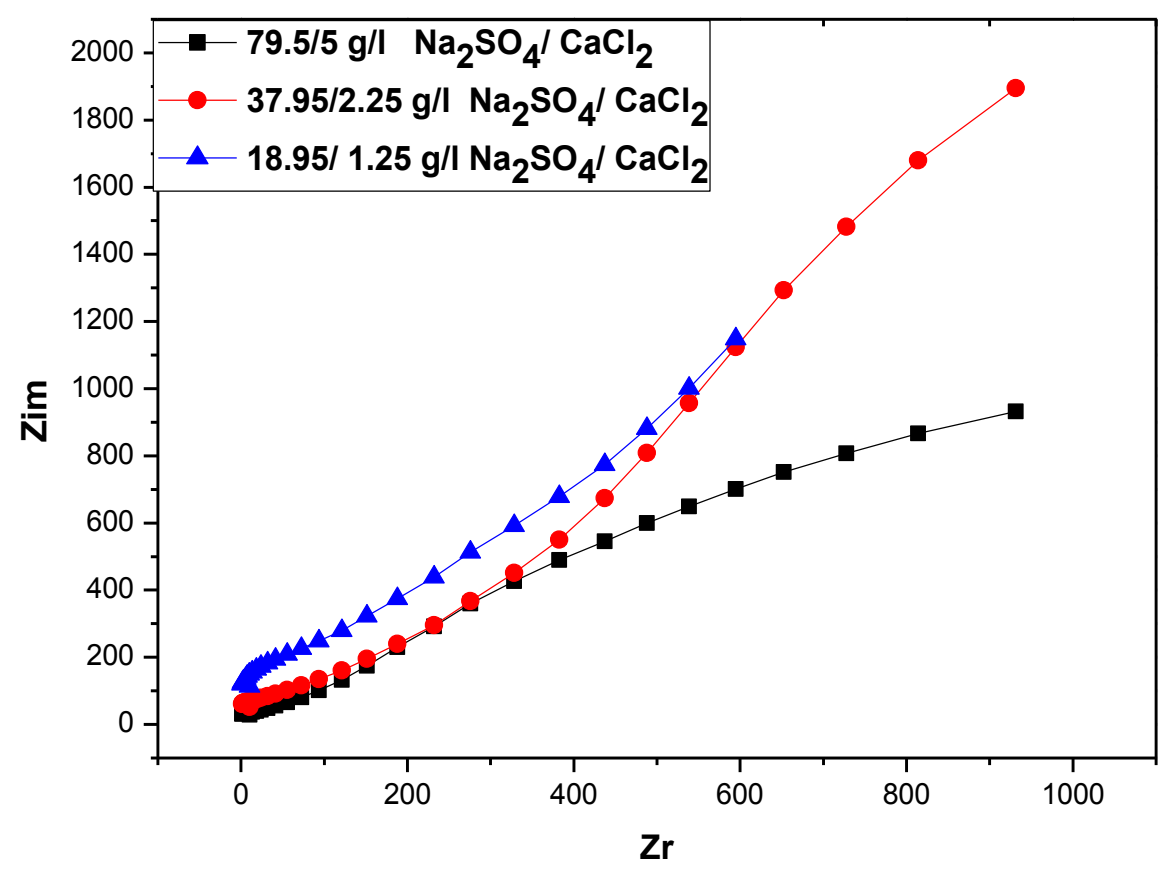

Figure 1. Nyquist diagrams recorded at different solution concentrations.

The diagrams of Nyquist presented in Figure 1 can be interpreted by a simple equivalent circuit Figure 2, where $R s$ is the solution resistance, and $C_{d l}$ and $R_{c t}$ are the double layer capacitance and the resistance of charge transfer respectively. 


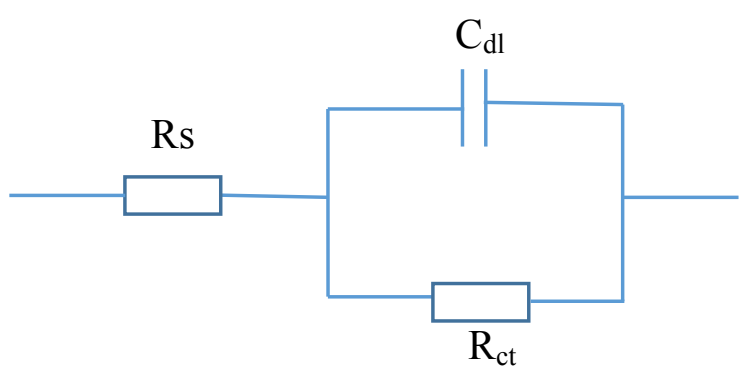

Figure 2. Equivalent electrical circuit corresponding to XC70 carbon steel /calcium sulphate interface.

Impedance data obtained from the equivalent circuit of figure 2 are presented in Table 1.

Table1. Data extracted from Nyquist diagrams of figure 1 .

\begin{tabular}{|c|c|c|c|c|c|}
\hline$C_{\mathrm{Na}_{2} \mathrm{SO}_{4}}(g / l)$ & $C_{\mathrm{CaCl}_{2}}(g / l)$ & $\mathrm{E}(\mathrm{mV})$ & $\mathrm{R}_{\mathrm{s}}\left(\Omega \cdot \mathrm{cm}^{2}\right)$ & $\mathrm{R}_{\mathrm{ct}}\left(\Omega \cdot \mathrm{cm}^{2}\right)$ & $\mathrm{C}_{\mathrm{dl}}\left(\mu \mathrm{F} \cdot \mathrm{cm}^{-2}\right)$ \\
\hline 79.5 & 5 & -622 & 8.37 & 206 & 121.8 \\
\hline 37.95 & 2.25 & -671 & 58.82 & 2.035 & 31.27 \\
\hline 18.37 & 1.25 & -679 & 22.59 & 1.76 & 22.59 \\
\hline
\end{tabular}

\section{1. Capacitance determination}

The value of the imaginary impedance of the equivalent electrical circuit presented in Figure 2, is given by the following equation 1,

$$
Z_{i m}=-\frac{w C R_{p}^{2}}{1+\left(i w R_{p} C\right)^{2}}
$$

at high frequency we obtain we can write,

$$
\left(i w R_{p} C\right)^{2} \gg 1
$$

Reporting equation 2 in 1 , we obtain the theoretical relation of the capacity of the precipitate of calcium sulphate, equation 3 ,

$$
C=\frac{1}{w Z_{\text {im }}}
$$


Equation 3 gives the experimental capacitance of calcium sulphate precipitate which can be conducted from the plot of logarithm of the imaginary part of the impedance $\log Z_{\text {im }}$ versus the logarithm of the frequency $\log f$ at different solution concentrations. Results are shown in Figure 3. The capacitance was obtained by extrapolation of the linear fitting of the obtained curve to the intersection with $\log Z_{i m}$.

Data obtained from curves of Figure 3 are regrouped in Table 2. As it can be seen experimental capacitance increase when solution concentration increase.

Table 2. Results of fitting of curves presented in Figure 3.

\begin{tabular}{|c|c|c|c|c|c|c|}
\hline$C_{\mathrm{Na}_{2} \mathrm{SO}_{4}}(g / l)$ & $C_{\mathrm{CaCl}_{2}}(g / l)$ & Equation & $\mathrm{R}^{2}$ & Inters & $\begin{array}{c}\mathrm{C} \\
(\mu \mathrm{F})\end{array}$ & $\mathrm{d}(\mathrm{nm})$ \\
\hline 79.5 & 5 & $\mathrm{y}=3.42171-0.70689 \mathrm{x}$ & 0.983 & 4.55419 & 0.558 & 0.62764 \\
\hline 37.95 & 2.25 & $\mathrm{y}=3.02788-0.54836 \mathrm{x}$ & 0.886 & 3.90638 & 2.481 & 0.141221 \\
\hline 18.37 & 1.25 & $\mathrm{y}=2.83697-0.4035 \mathrm{x}$ & 0.984 & 3.4834 & 6.571 & 0.049515 \\
\hline
\end{tabular}

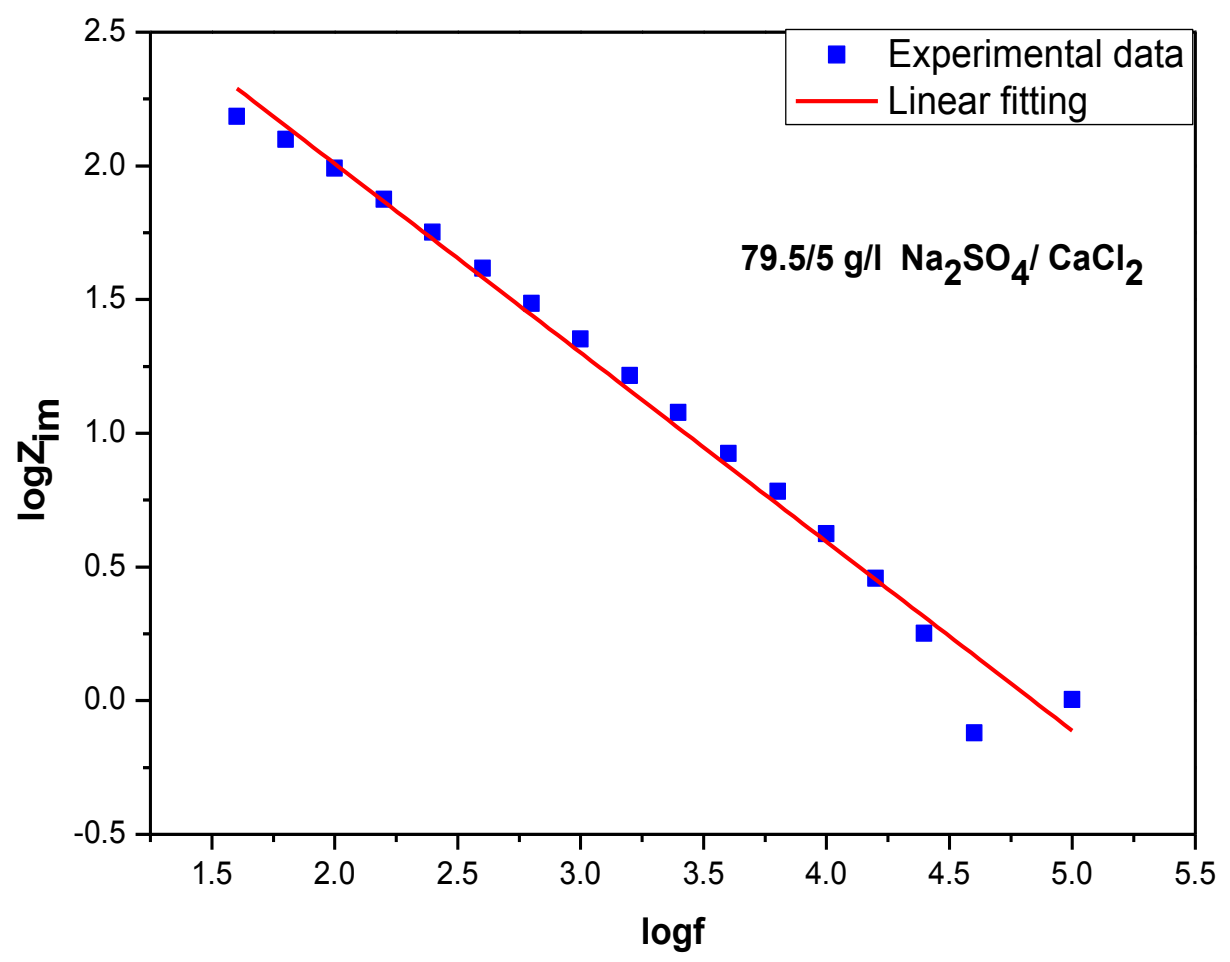



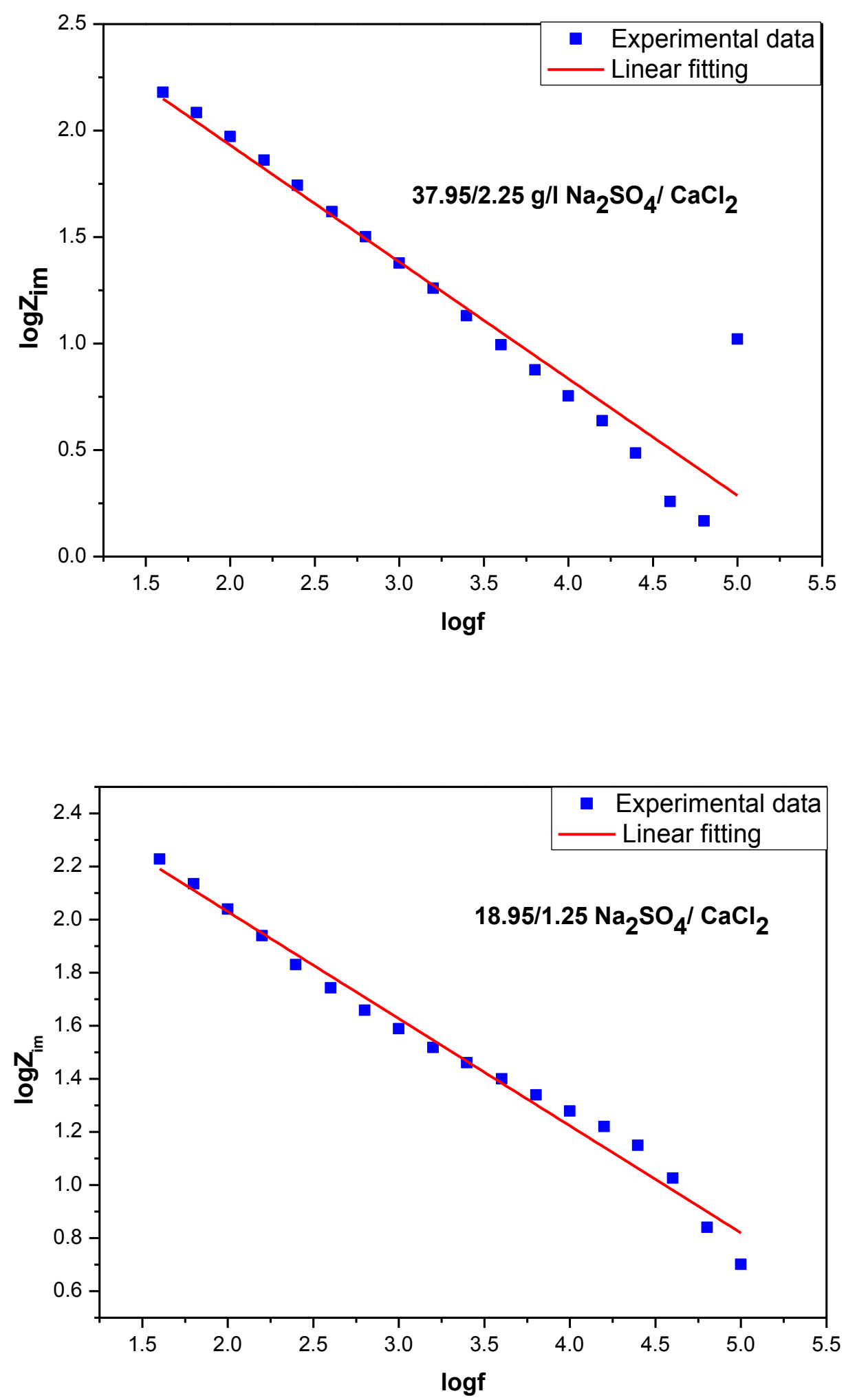

Figure 3. Fitting of curve $\log Z_{i m}$ versus $\log f$ at different solution concentrations. 


\section{2. Thickness measurement}

The thickness of calcium sulphate precipitate on XC70 carbon steel is calculated from the well-known relation that linking thickness precipitate to its capacitance, equation 4.

$$
d=\frac{\varepsilon \varepsilon_{0} A}{C}
$$

where $\varepsilon$ is the dielectric constant of calcium sulphate (5.6) [9], $\varepsilon_{0}$ is the primitive of vacuum $\left(8.85 .10-12 \mathrm{~F} \cdot \mathrm{m}^{-1}\right)$ and $\mathrm{A}$ is the exposed area of the working electrode $\left(0.707 \mathrm{~cm}^{2}\right)$. Results are shown in Table 3.

Table 3. Values of precipitate thickness as function of solution concentration.

\begin{tabular}{|c|c|c|}
\hline$C_{\mathrm{Na}_{2} \mathrm{SO}_{4}}(\mathrm{~g} / \mathrm{l})$ & $C_{\mathrm{CaCl}_{2}}(\mathrm{~g} / \mathrm{l})$ & $\mathrm{d}(\mathrm{nm})$ \\
\hline 79.5 & 5 & 0.6276 \\
\hline 37.95 & 2.25 & 0.1412 \\
\hline 18.37 & 1.25 & 0.0495 \\
\hline
\end{tabular}

Figure 4 show the independence of calcium sulphate film thickness on the solution concentration expressed as mol/l. Thickness of calcium sulphate precipitate increases when both concentration of sodium sulphate (Figure 4 (a)) and calcium chloride (Figure 4 (b)) increases.

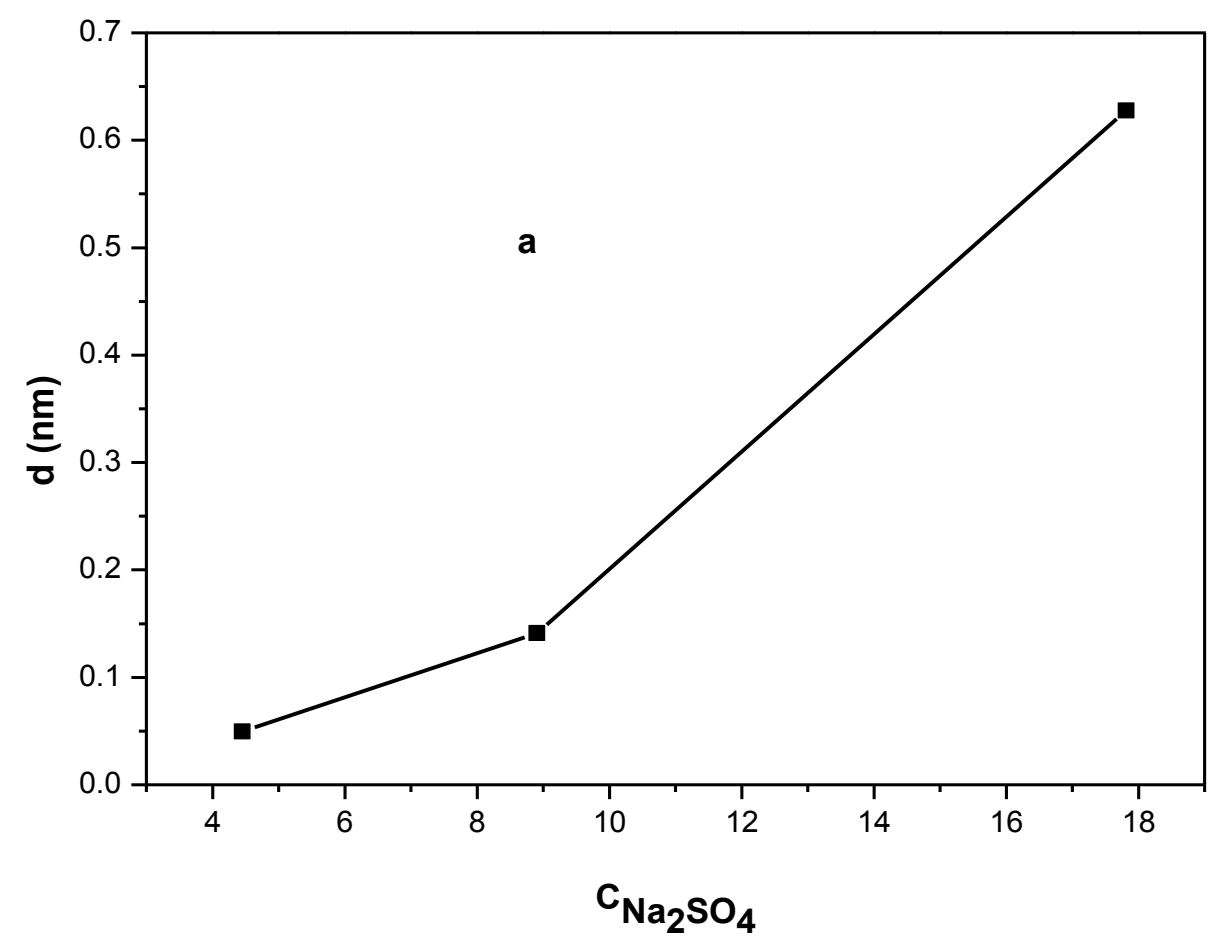




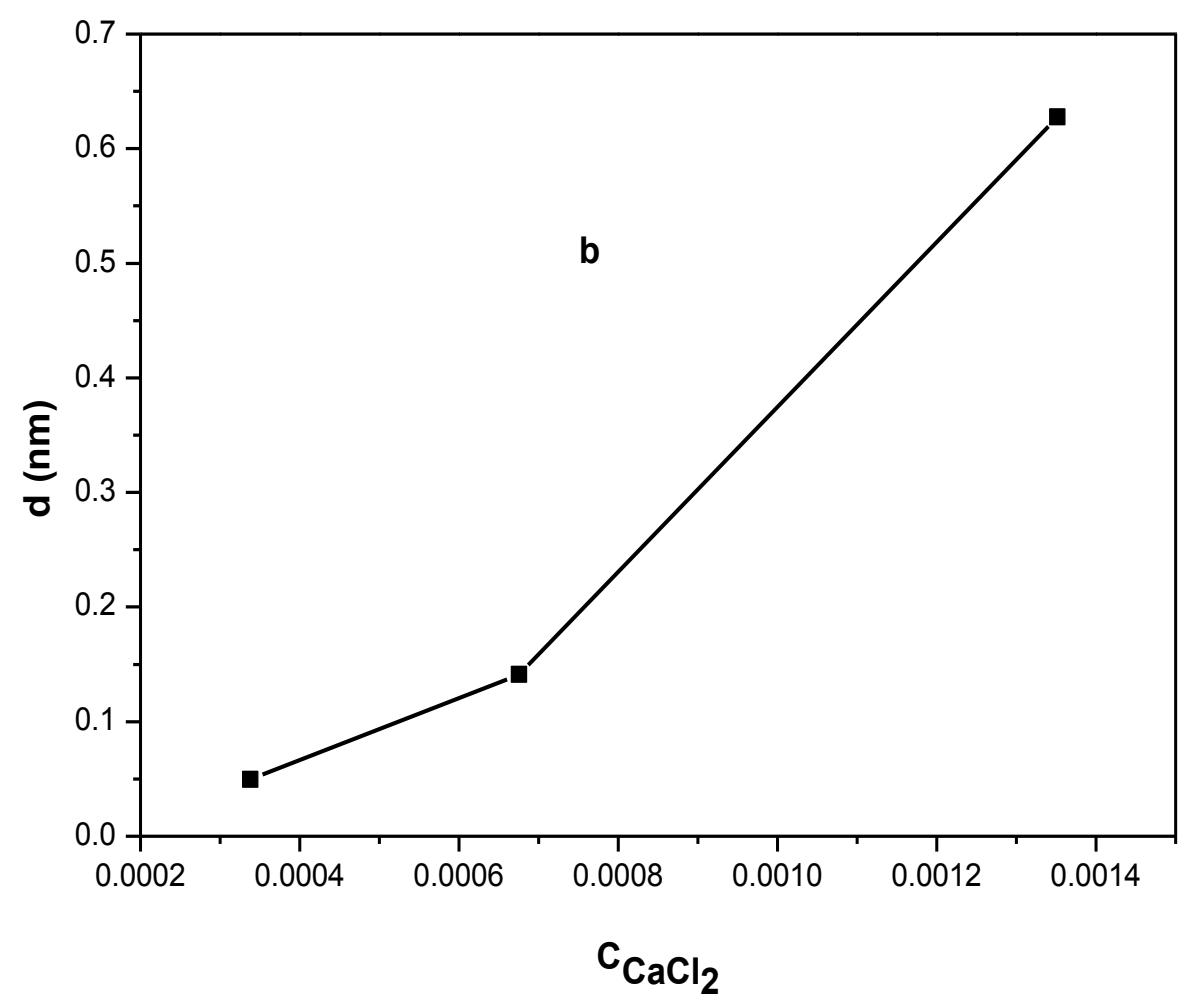

Figure 4. Variation of precipitate film thickness versus solution concentrations.

\section{CONCLUSION}

The thickness of calcium sulphate film formed on an XC70 carbon steel was estimated from capacitance determination using electrochemical impedance spectroscopy measurements in a mixture of sodium sulphate and calcium chloride solution. It has been found that film thickness increase when solution concentration increase.

\section{ACKNOWLEDGEMENTS}

Authors appreciate the financial support of this work by the Algerian Ministry of Higher Education and Scientific Research. We also thank Mr Ali Tliba laboratory staff for his help. 


\section{References}

[1] N. Bouzid, N. Settou, T. Lanez, A. Djelloul, A. A. Bebba, F. Chelgham, Revue des sciences de l'eau / Journal of Water Science 22(3) (2009) 397-406.

[2] J. Moghadasi, H. Muller-Steinhagen, M. Jamialahmadi, A. Sharif, J. Petrol. Sci. Eng. 43 (2004) 20-21.

[3] A. B. Bin Merdhah, A. A. Mohd Yassin, the Open Petroleum Engineering Journal 1 (2008) 62-73.

[4] M. Nassivera, A. Essel, The middle east oil techni-cal conference of the society of Petroleum Engineers, March 25-29, Manama, Bahrain, SPE 7765, 1979, pp. 133-138.

[5] A. P. Read, K. J. Ringen, The SPE sixth inter- national symposium on oilfield and geothermal chemistry, January 25-27, Dallas, Texas, SPE10593, 1983, pp. 7-17.

[6] J. O. Vetter, V. Kandarpa, A. Harouaka, J. Pet. Technol. (1982) 273-284.

[7] C. A. Todd, D. M. Yuan, SPE Production Engineering, SPE 19762, 1992, pp. 85-92.

[8] J. Moghadasi, M. Jamialahmadi, H. Muller-Steinhagen, A. Sharif, The SPE european formation damage conference, May 13-14, Hague, Netherlands, SPE 82233, 2003, pp.1-12.

[9] Dielectric constants of various materials, Document No. 99-00032, Date 7-17-97, Delta Controls Corporation. 